\title{
Movimientos de población en Andalucía y Cataluña (1995-2006). Una comparación desde la teoría de la modernización
}

\author{
José Fernando Troyano Pérez \\ Universidad de Málaga. Área de Sociología \\ jftroyano@uma.es
}

Recibido: 23-01-2008

Aceptado: 11-11-2008

\section{Resumen}

El propósito de este trabajo es comparar los movimientos de población de Andalucía y Cataluña durante los años 1995-2006 y relacionar este movimiento con la modernización social del período. Se utilizan como indicadores de modernización el nivel de renta declarado y los años de escolarización, y se diferencia el territorio según el tamaño demográfico del municipio. Las conclusiones se resumen de los modos siguientes.

La mejora en el nivel educativo se observa generalizada, salvo en los municipios andaluces menores $(\leq 2.000)$, envejecidos y despoblados, y en los andaluces y catalanes mayores (>100.000), repoblados mediante procesos de sustitución demográfica, evidentes en la Región Metropolitana de Barcelona y no en las mayores ciudades andaluzas. En cambio, se observa una relación, significativa en el caso catalán e importante en el andaluz, entre el crecimiento demográfico y el de los ingresos familiares.

En Andalucía (durante los años observados), el aumento de renta se ha debido al de población y la merma de renta ha sido efecto de la pérdida de población en bastante medida. No ha ocurrido de igual forma o en la misma medida en Cataluña. Ésta es una fórmula insostenible, puesto que no se puede mejorar a costa de crecer indefinidamente. Cabe concluir, pues, que la homogeneidad territorial es indicador y efecto de la modernización, pero también una condición y un factor para su continuidad.

Palabras clave: movimientos de población, modernización social, ingreso declarado, años de escolarización, tamaño de población del municipio, homogeneidad territorial.

Abstract. Population movements in Andalusia and Catalonia (1995-2006). A comparison from the perspective of modernization theory

The purpose of this study is to compare the movements of people from Andalusia and Catalonia during the years 1995-2006 and to link these movements with social modernization of the same period. The indicators used for this purpose are level of declared income and the years of schooling. The territory has been differed depending on the municipality population size. The findings are summarized in the following ways.

An improvement of the overall educational level is observed, except in smaller Andalusian municipalities $\leq 2000$, aged and depopulated, and in bigger $>100.000$ Andalusian and Catalonian municipalities, repopulated by demographic processes, evident in the Barcelona Metropolitan Region but not in the major cities of Andalusia. Instead, there is a significant relation between population growth and family income in both regions. 
In Andalusia (for the obseved years) was due to the increase of population and the loss of income was the effect of the loss of population as well. This was not the case in the same way or to the same extent in Catalonia. This formula is unsustainaible, since it is not possible to improved at the expense of indefinite growth. It can be concluded therefore that the territorial homogeneity is an indicator and territorial effect of modernization, but also a condition and a factor for its continuity.

Key words: population movements, social modernization, declared income, years of schoolings municipality population size, terrritorial homogenity.

\section{Sumario}

Teoría regional y modernización social

Los factores de la movilidad residencial

Algunos datos demográficos relevantes

El territorio y la urbanización
Migración interior y modernización

Epílogo y comentario

de las tablas anteriores

Referencias bibliográficas

\section{Teoría regional y modernización social}

El propósito de este trabajo es comparar los movimientos de población de Andalucía y Cataluña durante los años 1995-2006, utilizando datos del INE y de la base ASEP y relacionando este movimiento con la modernización social del período. Se compararán el movimiento natural de población y las distintas movilidades que las estadísticas agrupan en la denominación genérica de migración interior.

Las estadísticas utilizan la expresión migración interior como la más general para designar el cambio de municipio de residencia, bien dentro de la misma provincia, bien dentro de la misma comunidad pero distinta provincia, bien dentro del mismo país, cambiando de municipio y comunidad. Sin embargo, no es la distancia, sino el cambio en el modo de vida lo que define la migración y la diferencia de la movilidad residencial. Es obvio que algunas migraciones no conllevan un cambio en la actividad económica ni en el modo de vida, aunque desplazamientos de parecida longitud sí han conllevado esos cambios durante el siglo XX, cuando nuestros mayores migraban.

Con mayor probabilidad, sólo son actualmente migraciones las que se dirigen a una comunidad distinta; probablemente lo son también las que se dirigen a una provincia distinta, y sólo en algunos casos lo son las que se dirigen a otro municipio, con independencia de los tamaños de origen y destino y de la distancia entre ambos. Aunque se utilicen indistintamente las expresiones migración, movilidad geográfica, movilidad residencial y otras a lo largo del texto, se hará siempre siendo evidentes el origen y el destino del movimiento. En cambio, no se especifica cuando el desplazamiento implica una variación del modo de vida, cuando se llama movilidad a una migración.

¿Qué relación hay entre el movimiento de población y la modernización social? Una genérica relación teórica entre ambas puede enunciarse del siguiente 
modo. Las personas cambian de residencia y migran por variadas razones (que cubren desde la necesidad más básica al capricho), pero todas tienen una causa común: mejorar (algo futuro o presente, material o inmaterial). Mientras hay expectativa de mejora, es probable el movimiento. El sedentarismo implica el supuesto contrario: no se mejora migrando. El principio lógico de la relación entre migración o cambio residencial y modernización es la exigencia racional de mejorar (la racionalización weberiana, según la cual, lo que no crece, mengua).

Pero, además, la relación entre migración o cambio residencial y modernización está afectada por el principio de utilidad marginal decreciente: a partir de un determinado grado de bienestar material, la utilidad material del cambio residencial y la migración decrecen. Las expectativas han de ser, entonces, otras, un nuevo ideal de vida buena que contribuye a cimentar (junto a factores más económicos como el precio de la vivienda y la accesibilidad vial) la suburbanización: la búsqueda del menor tamaño urbano, la autonomía proporcionada por la vivienda unifamiliar (más imaginaria que real, con el gigantismo de la construcción horizontal), la convivencia comunitaria y la proximidad a una naturaleza urbanizada (sin las «incomodidades» de la naturaleza en su estado natural).

Las dificultades de aplicar el supuesto de que a mayor modernización mayor movilidad a la realidad histórico-demográfica son metodológicas y teóricas. Las metodológicas conducen para su solución a diferenciar los diferentes fenómenos que se agrupan en la denominación genérica de movimiento de población: el movimiento natural, las migraciones, los cambios de residencia y la movilidad recurrente. Las mayores dificultades teóricas son consecuencia de que a mayor modernización no acompañan mayores movimiento y movilidad, como alguna interpretación de la modernización induce a concluir, sino distintos movimiento y movilidad. Más de la mitad de los residentes en la ciudad de Nueva York han nacido en el extranjero. En las grandes ciudades norteamericanas y europeas hay una mayor proporción de residentes extranjeros que en las africanas, y en las ciudades más ricas y modernizadas residen más foráneos que en las más pobres y atrasadas, pero ¿por qué hemos de atribuir esa movilidad a las sociedades receptoras y no a las expulsoras? ${ }^{1}$. Parece obvio que la inmigración es un indicador de modernización, pero también de movilidad inducida, y esa inducción tiene causas tanto en la sociedad o en el territorio receptores (modernizados) como en los expulsores (no o menos modernizados). Ni la inmigración ni el saldo migratorio son evidencia por sí solos a favor o en contra de la modernización del territorio de referencia, porque no son efectos de un fenómeno endógeno, propio o exclusivo de ese territorio o esa sociedad. El saldo migratorio entre dos o más sociedades sólo puede explicarse y comprenderse como resultante de las relaciones entre ellas, y no del estado de una sola, y los efectos de esa migración lo serán igualmente de esa relación.

1. Ni éste es lugar para plantearlo con un mínimo de rigor, ni estoy capacitado para hacerlo de ese modo, pero sospecho que detrás de esta atribución en exclusiva están las dificultades de la sociología para incluir el espacio en sus análisis. Imaginar dos regiones como vasos comunicantes podría ser un ejemplo de estas dificultades. 
En Cataluña hay mayor proporción de personas nacidas en Andalucía que a la inversa, por efecto de la atracción durante décadas de su mayor desarrollo y modernización. Pero la proporción de andaluces residentes en Cataluña ha descendido durante las tres últimas décadas, mientras la sociedad catalana ha continuado su proceso de modernización. La explicación parece fácil: Andalucía también se ha modernizado, lo cual ha reducido su emigración. Pero, entonces, no siendo evidente una relación directa, según la cual, a más modernización, menos previsible es la residencia (como cualquier otra elección), es decir, menos cambios de residencia (al contrario de lo que se deduciría de una comparación entre España y Dinamarca), ¿cuál o cómo es la relación entre movilidad y modernización?2.

La relación entre alternativas laborales y residenciales es un tópico de la teoría social y una asociación del sentido común y la experiencia histórica. El mercado ha movilizado los recursos durante los siglos XIX y XX con una amplitud e intensidad sin precedentes. Desde una perspectiva que combina la sociología, la economía y la historia, la teoría del sistema mundial ha hecho de la universalización del mercado su objeto (Wallerstein, 1979). Desde otra perspectiva más económica y más centrada geográficamente, se denominaron teorías del crecimiento regional a un conjunto de estudios que, desde mediados del pasado siglo, han relacionado el desarrollo económico con factores como la migración ${ }^{3}$. Estas teorías se agrupan en tres enfoques. Uno sostiene que el proceso de crecimiento equilibra las desigualdades regionales ${ }^{4}$, pues el crecimiento moviliza los factores productivos (capital y trabajo), lo cual favorece la convergencia de renta per cápita (Hoover, 1948). Otro sostiene lo contrario, que la riqueza llama a la riqueza y a la concentración demográfica: las regiones ricas son cada vez más ricas y pobladas (acumulan recursos), y las pobres, cada vez más pobres y despobladas (pierden recursos) (Myrdal, 1959). Un tercer enfoque se sitúa entre los anteriores, diferencia entre desarrollo intrarregional e interregional y concluye que, en el primero, se produce divergencia entre áreas y, en el segundo, convergencia entre regiones (Richardson, 1976).

El efecto homogeneizador (intrarregional e interregional) de la modernización ha sido destacado en una comparación anterior entre Andalucía y Cataluña (Gobernado, 1996), que contempla la modernización extendiéndo-

2. Es lugar común que la migración ha ayudado a desarrollar y modernizar regiones o países expulsores, como Andalucía y España, y receptores, como Cataluña y Alemania, durante el pasado siglo, pero no tuvo el mismo efecto en Irlanda ni lo tiene actualmente en África. Más adelante se harán referencias bibliográficas a este respecto.

3. La relación entre convergencia interregional y migración y entre migración y nivelación del desempleo y los salarios se ha explicado desde distintas escuelas y perspectivas económicas. Es el objeto más que la perspectiva lo que agrupa estos estudios en la teoría del desarrollo regional.

4. Por región entiende la teoría y entendemos en este texto un territorio, histórica, cultural o administrativamente definido, que forma parte, junto con otros de similares características, de una entidad mayor, dentro de la cual la movilidad de los recursos no presenta restricciones administrativas. 
se como una mancha de aceite, según un proceso típico en forma de S. Una imagen que representa dos ideas diferentes: la forma de extenderse (como el aceite sobre una superficie de mayor densidad) y la forma de crecer (en S, como la «transición demográfica»). Comoquiera que se señale la falta de acoplamiento de recursos productivos ${ }^{5}$, si el proceso de modernización tiene forma de $S$, a partir de un cierto valor de renta o bienestar, la población reducirá su movilidad motivada por razones productivas, sin perjuicio de que se mantenga un grado de desacoplamiento y de que aumente la movilidad general por otras causas. Esos valores de renta y bienestar vendrán fijados por el estancamiento de la movilidad espacial de acoplamiento y el desarrollo de otros tipos de movilidad espacial.

Algunas investigaciones han puesto en entredicho la relación entre convergencia salarial y migración interregional (Rosés y Sánchez Alonso, 2004), que la migración interregional sea un mecanismo efectivo para reducir las diferencias de desempleo entre regiones (Hughes y McCormick, 1994; McCormick, 1997; Molho, 1995; Antolín y Bover, 1997; Bentolila, 1997; Faini y otros, 1997; Groenewold, 1997), pero la mejor teoría posee excepciones y contradicciones, y si alguna pretendiese explicar la historia universal, acabaría tropezándose con ella o no encontrándola nunca (si sus previsiones son sine die). Como ha defendido Paul Krugman: «...la modelización, aunque pueda parecer simplista, es en la práctica una disciplina que evita que uno sea aún más simplista.» (Krugman, 1997).

El objetivo de este trabajo se limita al postulado de la homogeneidad, referido a un tiempo pasado y concreto. Comprobaremos si Andalucía y Cataluña son más homogéneas y si están más próximas o más distantes al inicio que al final del período 1995-2006, y relacionaremos esta homogeneidad o heterogeneidad con el movimiento de población, tanto natural (vegetativo), como inducido por la movilidad geográfica (cambio residencial y migraciones).

\section{Los factores de la movilidad residencial}

Entre los factores de la movilidad residencial, la experiencia investigadora ha destacado: el ciclo de vida familiar (el calendario de constitución, consolidación y disolución de los hogares) (Módenes, 2000; Antolín y Bover, 1997; Chan, 1996; Bonvalet y Fribourg, 1990; Clark y Onaka, 1982; Rossi, 1955), la forma de tenencia de la vivienda (propiedad o alquiler) (Grafmeyer y Dansereau, 1998; Myers, 1990), la inserción laboral, la localización relativa (a la

5. Herrera y Gobernado utilizaron el recurso conceptual de "población desacoplada» para indicar la diferencia en el cociente producción/población y explicar la migración como un mecanismo de acoplamiento entre recursos productivos. En puridad, son los recursos población y capital los desacoplados, pues, aun siendo la medición de la homogeneidad el único propósito del concepto, tanto se puede hablar de exceso de población como de defecto de capital, ya que lo que define el acoplamiento o el desacoplamiento es la relación entre ambos recursos. 
residencia) del puesto de trabajo (Módenes, 2000; Böheim y Taylor, 1999; Henley, 1998), el estatus socioeconómico (formación reglada, actividad y renta) (Martínez Torres, 2005; Lelièvre y Lévy-Vroelant, 1992; Ascher, 1995), las redes sociales (Solana, De Miguel y Cardelús, 2004) y las fases del ciclo económico (Recaño y Cabré, 2004; Alberich, 2003; Feria Toribio y Susino Argucias, 2001).

Estos factores mediatizan la relación entre movilidad residencial y modernización, al ser también variables que definen directamente la modernización. Una sociedad (modernizada) donde los individuos son actores sociales a más temprana edad, cumple mejores condiciones para la más temprana emancipación. Una sociedad (modernizada), que ha hecho del trabajo una elección (jurídicamente) libre para hombres y mujeres, favorece mayores cambios de actividad y, consecuentemente, debe también favorecer más variaciones residenciales. Una sociedad más rica o en crecimiento económico favorece un mejor acceso a la vivienda (cualquiera que sea el régimen de tenencia). Una sociedad (modernizada) ha diferenciado espacialmente las funciones productiva y residencial, y, en consecuencia, favorece más opciones residenciales. Una sociedad (modernizada) que favorece el individualismo y la individuación reduce el juego mediador de las redes familiares y locales, con lo cual posibilita alternativas residenciales y migratorias no previsibles en otras sociedades.

En la relación entre estos factores y el grado de movilidad residencial se centran las explicaciones del fenómeno. Más difícil es obtener una forma (o fórmula) de relación entre modernización y movilidad residencial, ya que la probabilidad de residir y fallecer en una provincia distinta de la de nacimiento creció en España durante el siglo XX hasta el censo de 1981. La migración interregional ha contribuido al ajuste en el pasado, pero poco en los últimos veinte años y menos en los últimos diez, pese a que la diferencia de renta continúa (el PIB per cápita ha sido, en 2005, de 24.804 euros en Cataluña y de 19.343 en Andalucía ${ }^{6}$ ) y a que las posiciones relativas al conjunto español de Andalucía y Cataluña apenas han variado.

Una buena muestra de lo expuesto la proporcionan los datos de ASEP, base que se ha utilizado en otros apartados de esta investigación y que contiene datos recabados mediante dos encuestas, una del año 1995 y otra del 2006. En la encuesta de este último año, se ha preguntado al encuestado la provincia de nacimiento (las respuestas no aparecen para 1995). La siguiente tabla (tabla 1) resulta de cruzar la provincia de residencia actual con la de nacimiento e informa de quienes residen en la misma provincia donde nacieron (columna numérica izquierda) y de quienes residen en la misma comunidad donde nacieron (columna numérica derecha).

Durante los últimos cincuenta años (la edad media de la muestra es de 44 años para los residentes en Andalucía y de 46 para los residentes en Cataluña),

6. Aun más favorable a Cataluña en su comparación con Andalucía son los datos de la Encuesta de calidad de vida 2005, que establece una renta media por persona de 6.454 euros en Andalucía y 9.109 en Cataluña. 
Tabla 1. Residentes en la provincia y en las comunidades autónomas de nacimiento según comunidad autónoma y provincias en el año 2006

\begin{tabular}{lll}
\hline & $\begin{array}{l}\text { Residen en la provincia } \\
\text { de nacimiento }(\%)\end{array}$ & $\begin{array}{l}\text { Residen en la comunidad } \\
\text { de nacimiento (\%) }\end{array}$ \\
\hline Andalucía & 73,18 & 77,97 \\
\hline Almería & 63,13 & 65,92 \\
Cádiz & 83,68 & 88,95 \\
Córdoba & 60,92 & 64,61 \\
Granada & 65,58 & 73,05 \\
Huelva & 81,77 & 87,50 \\
Jaén & 50,42 & 57,70 \\
Málaga & 86,83 & 90,13 \\
Sevilla & 82,55 & 85,97 \\
\hline Cataluña & 87,56 & 93,81 \\
\hline Barcelona & 89,34 & 93,45 \\
Gerona & 86,40 & 97,60 \\
Lérida & 75 & 94,05 \\
Tarragona & 80 & 93,33 \\
\hline
\end{tabular}

Fuente: ASEP, 2006.

ha migrado (sin retorno) a otras comunidades españolas un 22,03\% de andaluces (de nacimiento) y un 6,19\% de catalanes (de nacimiento). Los catalanes migran mayormente dentro de Cataluña y los andaluces fuera de Andalucía. Ejemplar del lado catalán es el caso de la provincia de Lérida, que presenta un porcentaje de salidas provinciales más parecido a los andaluces que a los otros catalanes, pero no uno de salidas de la comunidad, pues 19 de cada 25 emigrados de Lérida residen en Cataluña.

La migración interior en Cataluña supera a la exterior en el conjunto y en tres de las cuatro provincias, salvo en Barcelona, pues sus naturales residen más en el resto de España $(6,55 \%)$ que en el resto de Cataluña (4,11\%). Pese a que su PIB per cápita es el menor de la comunidad y su tasa de paro, la mayor, la provincia de Barcelona es el destino de la mayoría de los migrantes catalanes. En cualquier caso, su atracción puede retener, pero no atraer a quien ya es residente.

Por contraste, en Andalucía, más migración ha conllevado más emigración exterior, hasta fechas recientes en el conjunto de la comunidad y aún más recientes en algunas provincias (véanse las tablas 8 y 9). 


\section{Algunos datos demográficos relevantes}

Aunque el peor dato quizás sea de 1998: el menor crecimiento vegetativo conocido en España (4.682), 1996 fue un año destacado demográficamente, pues la natalidad española alcanzó su valor registrado más bajo, 362.626 nacimientos. En 1996, las poblaciones de Cataluña y Andalucía eran de 6.090 .040 y de 7.234.873 de habitantes, respectivamente, y su crecimiento en los diez años anteriores había sido "preocupante». En 1986, Andalucía tenía 6.789 .770 habitantes y Cataluña, 5.978.678. El aumento relativo del decenio 1986-1996 había sido del $106,55 \%$ en Andalucía y del $101,86 \%$ en Cataluña. Pero en 2006 ya sumaban 7.134.697 (Cataluña) y 7.975.672 (Andalucía) habitantes. En estos diez años, el aumento ha sido del 110,24\% para Andalucía y del $117,15 \%$ para Cataluña (tabla 2). Un crecimiento muy diferente al del decenio anterior, sobre todo en Cataluña.

El punto de inflexión en estos veinte años hay que situarlo en el 2001, con un incremento de casi 100.000 residentes en Cataluña, que serán cerca de 150.000 en el 2002 y de 200.000 en el 2003. Desde 2001, los incrementos de población han sido siempre superiores en Cataluña que en Andalucía (tabla 3). Durante los años 2004 y 2005, el mayor crecimiento demográfico de Cataluña se ha debido directa o indirectamente (a través de la fecundidad diferencial) a la entrada de población extranjera desde el exterior.

En 1996, el crecimiento vegetativo (nacidos menos fallecidos) de la población andaluza fue de 18.619 personas y el de la población catalana, de 822 . En 2005, estos crecimientos fueron de 25.903 personas en Andalucía y 17.989 en Cataluña. Se habían multiplicado por 1,39 y por 21,88 , respectivamente. Tras la de Madrid, fueron las comunidades que más contribuyeron al crecimiento demográfico español.

Este hecho se explica en gran medida por el diferente peso de la población inmigrada en ambas regiones y su fecundidad diferencial. España sumó, en el año 2000, cuarenta millones de habitantes. (En 2007, esa suma ascendió a cuarenta y cinco millones de residentes.) El punto de inflexión en la entrada de extranjeros se produjo también el mismo año 2000, a raíz de un proceso extraordinario de regularización. Desde entonces, las entradas desde el exterior de extranjeros a España, Cataluña y Andalucía han sido las que resume la tabla 4.

Tabla 2. Crecimiento absoluto y relativo de población según comunidad autónoma y décadas

\begin{tabular}{lllllll}
\hline & $\mathbf{1 9 8 6 - 1 9 9 6}$ & & & $\mathbf{1 9 9 6 - 2 0 0 6}$ & \\
\cline { 2 - 3 } & $\begin{array}{l}\text { Crecimiento } \\
\text { absoluto }\end{array}$ & $\begin{array}{l}\text { Crecimiento } \\
\text { relativo }\end{array}$ & & $\begin{array}{l}\text { Crecimiento } \\
\text { absoluto }\end{array}$ & $\begin{array}{l}\text { Crecimiento } \\
\text { relativo }\end{array}$ \\
\hline Andalucía & 445.103 & 106,55 & & 740.799 & 110,24 \\
Cataluña & 11.362 & 101,86 & & 1.044 .657 & 117,15 \\
\hline
\end{tabular}

Fuente: INE. Elaboración propia. 
Tabla 3. Información demográfica según comunidad autónoma y años

\begin{tabular}{|c|c|c|c|c|c|c|c|c|}
\hline \multirow[b]{2}{*}{ Año } & \multicolumn{4}{|l|}{ Andalucía } & \multicolumn{4}{|l|}{ Cataluña } \\
\hline & Población & CI & $\mathrm{CA}$ & $\mathrm{CV}$ & Población & CI & $\mathrm{CA}$ & $\mathrm{CV}$ \\
\hline 2001 & 7.403.968 & & 100 & 2,88 & 6.361 .365 & & 100 & 1,37 \\
\hline 2002 & 7.478 .432 & 101 & 101 & 2,72 & 6.506 .440 & 102,3 & 102,3 & 1,66 \\
\hline 2003 & 7.606 .848 & 101,7 & 102,7 & 2,84 & 6.704 .146 & 103 & 105,4 & 1,90 \\
\hline 2004 & 7.687 .518 & 101,1 & 103,8 & 3,41 & 6.813 .319 & 101,6 & 107,1 & 2,87 \\
\hline 2005 & 7.849 .799 & 102,1 & 106 & 3,35 & 6.995 .206 & 102,7 & 110 & 2,62 \\
\hline 2006 & 7.975 .672 & 101,6 & 107,7 & & 7.134 .697 & 102 & 112,1 & \\
\hline
\end{tabular}

CI (crecimiento interanual), CA (crecimiento acumulado), CV (crecimiento vegetativo x 1000). Fuente: INE. Elaboración propia.

Tabla 4. Entradas de extranjeros desde el exterior en España y en cada comunidad autónoma según años

\begin{tabular}{lrrrrrr}
\hline & \multicolumn{1}{c}{2000} & \multicolumn{1}{c}{2001} & \multicolumn{1}{c}{2002} & \multicolumn{1}{l}{2003} & \multicolumn{1}{c}{2004} & \multicolumn{1}{c}{2005} \\
\hline España & 330.881 & 394.048 & 443.085 & 429.524 & 645.844 & 682.711 \\
Andalucía & 29.022 & 35.989 & 50.097 & 53.256 & 89.377 & 94.070 \\
Cataluña & 30.543 & 43.499 & 56.747 & 55.576 & 149.705 & 157.375 \\
\hline
\end{tabular}

Fuente: INE.

El porcentaje de recepción de extranjeros en ambas comunidades es inferior a su porcentaje de población en el conjunto español hasta el 2004. Durante 2004 y 2005, sigue siéndolo para Andalucía, que recibe al 13,8\% de la población extranjera llegada a España, mientras que Cataluña salta por encima del 23\%. Cabe subrayar también que en Andalucía esta población inmigrada extranjera se asienta de forma más extensiva a lo ancho del territorio, pues, mientras que la provincia de Málaga acogía a 6/10 de los llegados en 1999, a partir de 2000 Almería contribuye de forma importante a la recepción, de modo que en 2005 Málaga recibe al 33,2\% y Almería al 25,6\% de los extranjeros llegados desde el exterior hasta Andalucía.

En Cataluña ocurre lo contrario, Barcelona concentra en estos años la recepción de extranjeros procedentes del exterior: en 2000, al 61,8\% y en 2005, al 69,5\%. El peso demográfico de los extranjeros en Cataluña es bastante mayor que en Andalucía, pues en el año 2006 los extranjeros residentes en Andalucía eran 488.928, el 6,1\% de la población andaluza, mientras que en Cataluña eran 913.757 , el $12,8 \%$ de la población catalana. Gracias a esta numerosa población extranjera, Cataluña ha salido en los últimos años de un estancamiento demográfico de décadas, pese a que su saldo migratorio interior ha sido negativo durante los últimos años (tabla 5). 
Tabla 5. Saldos migratorios interiores, provinciales y autonómicos

\begin{tabular}{lrrrrrrr}
\hline & 2006 & 2005 & 2004 & 2003 & 2002 & 2001 & 1995 \\
\hline Andalucía & 6.079 & 12.175 & 13.909 & 10.670 & 3.062 & -1.932 & 3.391 \\
\hline Almería & -2.349 & -115 & -1.215 & -1.205 & -2.420 & -718 & 7.995 \\
Cádiz & 1.319 & 1.580 & 3.451 & 2.629 & 1.373 & -408 & -2.863 \\
Córdoba & -673 & -943 & -523 & -288 & -1.168 & -2.018 & -1.451 \\
Granada & 1.071 & 2.176 & 1.252 & 1.793 & 90 & -236 & -1.173 \\
Huelva & -541 & 1.826 & 35 & -72 & -390 & -338 & 216 \\
Jaén & -1.498 & -1.648 & -750 & -988 & -1.297 & -1.698 & -2.119 \\
Málaga & 5.344 & 5.555 & 8.647 & 7.032 & 6.280 & 4.264 & 2.238 \\
Sevilla & 3.406 & 3.736 & 3.012 & 1.769 & 594 & -780 & 528 \\
\hline Cataluña & -11.762 & -9.776 & -2.988 & 1.017 & 1.549 & 1.458 & -3.468 \\
Barcelona & -25.552 & -20.419 & -20.227 & -16.386 & -12.224 & -8.353 & -10.439 \\
Gerona & 4.019 & 3.670 & 6.680 & 7.143 & 5.786 & 3.604 & 2.328 \\
Lérida & 160 & -1.982 & 661 & 1.720 & 864 & 461 & 392 \\
Tarragona & 9.611 & 8.935 & 9.898 & 8.540 & 7.123 & 5.746 & 4.251 \\
\hline
\end{tabular}

Fuente: INE.

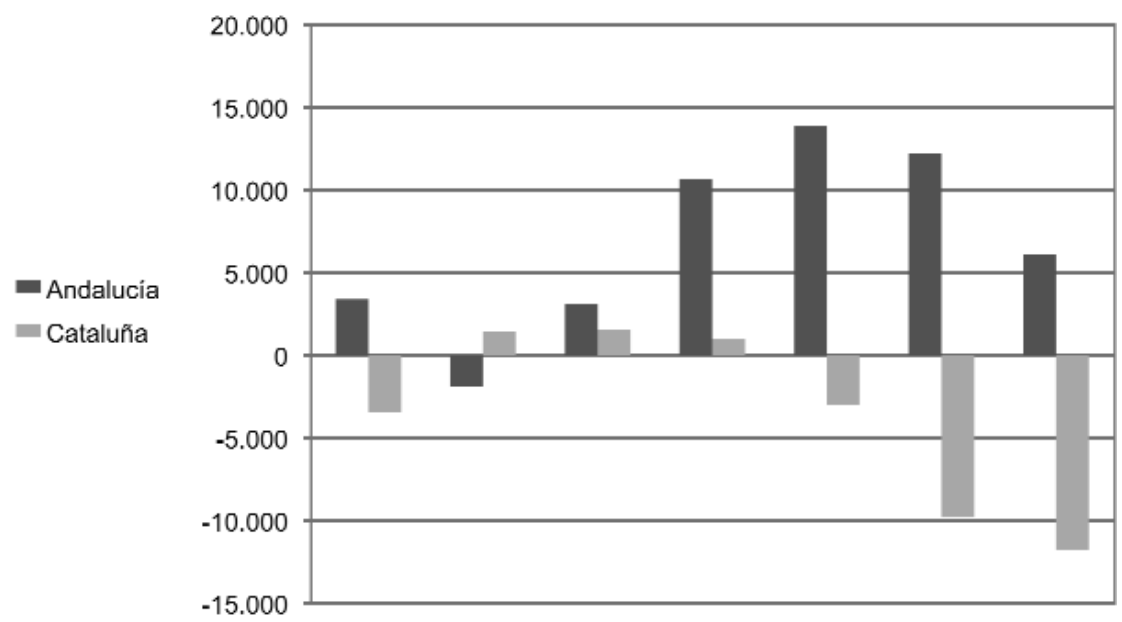

Gráfico 1. Saldos migratorios interiores según comunidad autónoma y año. Fuente: datos de la tabla 5 . 


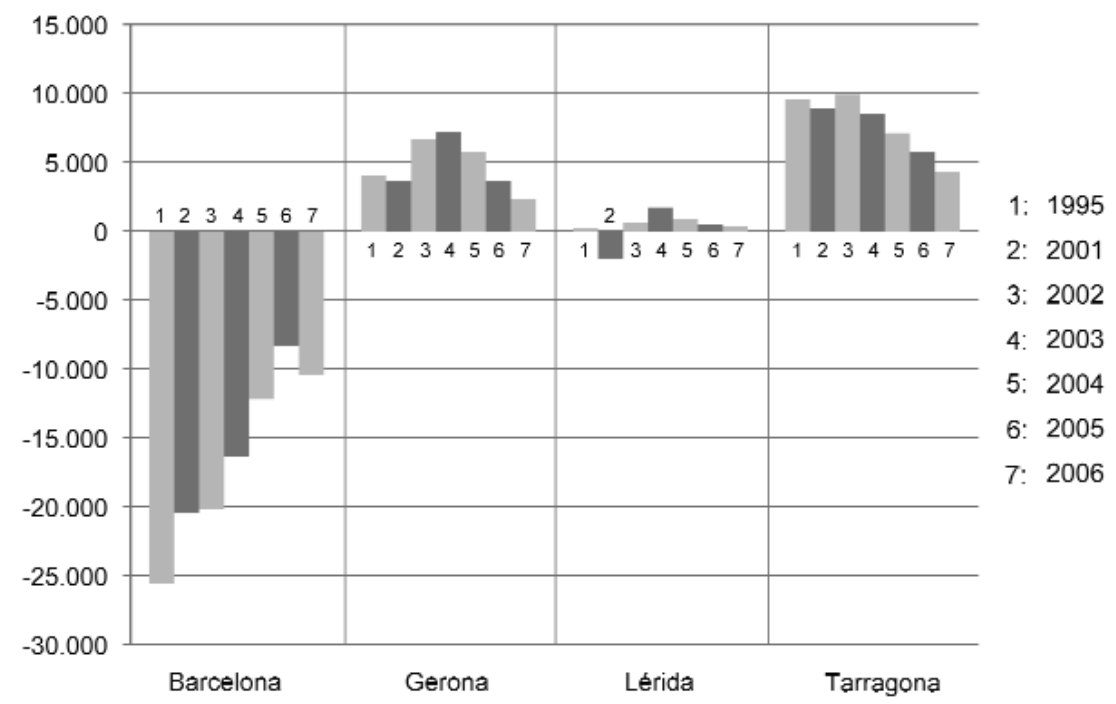

Gráfico 2. Saldos migratorios interiores en Cataluña según provincia y año. Fuente: datos de la tabla 5.

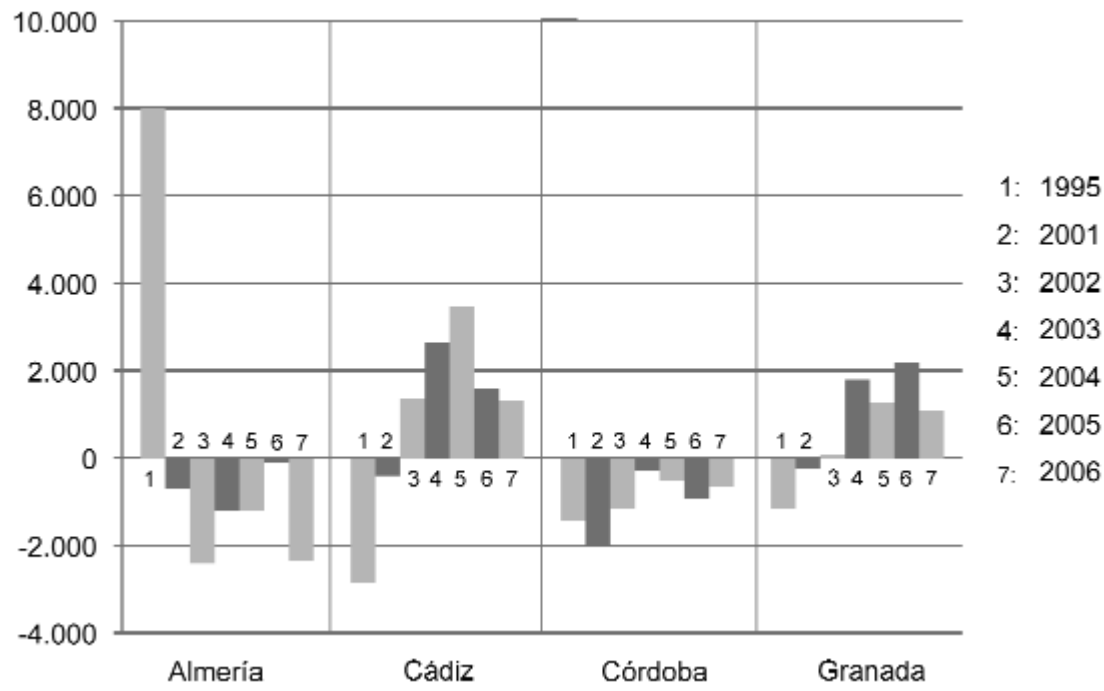

Gráfico 3. Saldos migratorios interiores en Andalucía según provincias y año. Fuente: datos de la tabla 5. 


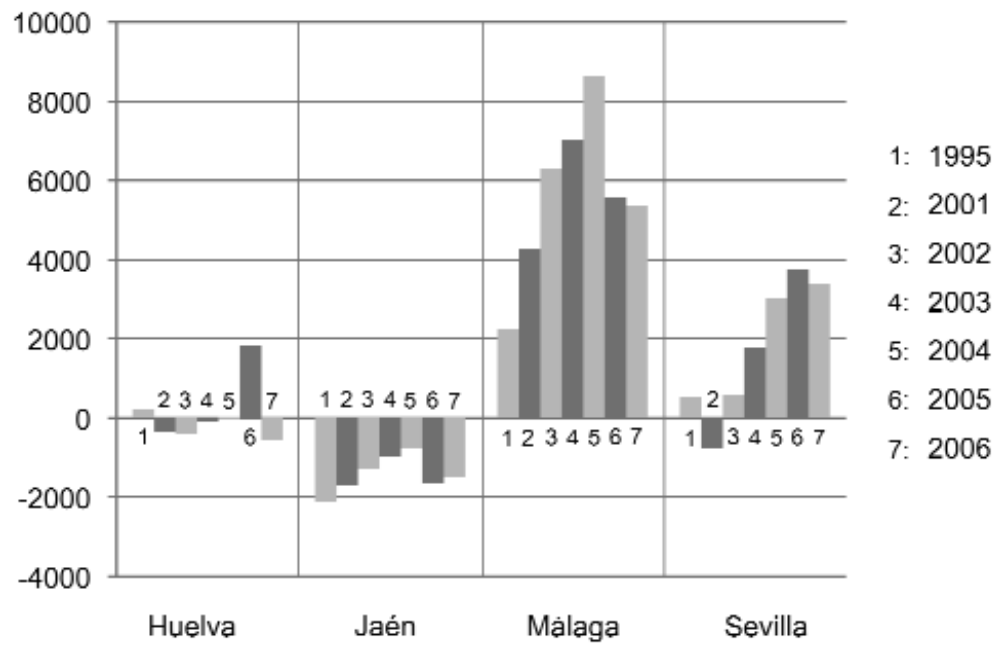

Gráfico 4. Saldos migratorios interiores en Andalucía según provincias y año. Fuente: datos de la tabla 5 .

Cataluña se ha convertido, durante los últimos años, en un destino atractivo para la inmigración extranjera y ha dejado de serlo para la población nacional (como lo ha sido durante décadas). La «mitad» de atractiva es actualmente Andalucía para la inmigración extranjera y algo más que Cataluña para la población nacional, dentro de una pauta general de escasa movilidad geográfica de los españoles, especialmente entre comunidades.

\section{El territorio y la urbanización}

El supuesto que asocia un modo de vida con un tamaño de población continúa siendo realista y operativo, responde a una lógica social aún vigente: el vínculo social, la identidad, la economía y el volumen de población se relacionan. Pero se presta a confusión cuando el criterio para medir el tamaño de una población no es demográfico, sino territorial. Las estadísticas de población miden realidades orgánicas, los individuos, mientras que los términos municipales viven y se transforman por decisión administrativa. Los términos municipales son comparables por su extensión y por su población, pero las poblaciones y sus modos de vida no son comparables por la extensión del término municipal en el que se asientan. Semejante comparación asocia de forma invariable el territorio, la población y la sociedad (un modo de vida).

El término municipal de Barcelona alcanzó su número más elevado de población en 1981, con 1.752.627 habitantes. Después decreció durante vein- 
te años, junto con otros municipios de su área metropolitana. En el censo de 2006, Barcelona suma 1.605.602 habitantes. Pero esta pérdida demográfica no significa un retroceso de la urbanización, sino justamente lo contrario: la estrechez del municipio para contener el expansivo proceso de urbanización, que hace veinte años se expandía ya desde el centro hasta la corona metropolitana. La cuestión ahora es si el proceso de expansión urbana continúa más allá de sus límites anteriores o si, por el contrario, se está produciendo un reencuentro intencionado de la población con el hábitat rural. Como señala Isabel Pujadas (Pujadas, 2005):

Desde principios de los años ochenta, las tasas de inmigración [en la Región Metropolitana de Barcelona] son inversamente proporcionales al tamaño de población, de manera que cuanto más pequeño es el municipio, mayor es la inmigración y a la inversa, cuanto mayor es la ciudad, menor es la inmigración. Proceso que se acentúa en la década de los noventa. Se ha invertido totalmente la jerarquía de la inmigración que durante decenios, o bien siglos, había marcado el proceso de urbanización. Se cumple en la Región Metropolitana de Barcelona el modelo que Fielding (1982) aplicó a la evolución de las tasas de migración en las áreas metropolitanas de los países de la Europa Occidental. Sin ninguna duda éste será uno de los elementos más significativos del nuevo modelo de crecimiento urbano: el mayor crecimiento de los pequeños pueblos y pequeñas ciudades de las periferias metropolitanas.

Andalucía contaba en el 2006 con doce municipios de más de 100.000 habitantes y Cataluña con $\mathrm{diez}^{7}$. Limitar o graduar el modo de vida urbano dependiendo de los límites territoriales de estos veintidós municipios se presta a equívocos, como el de llamar hábitat al territorio definido por el término municipal ${ }^{8}$.

La estructura de población por rangos municipales y su más reciente evolución (1996-2006) se resumen en la tabla 6.

Ahora bien, entre el año 1996 y el 2006, las poblaciones de Andalucía y Cataluña aumentaron en 740.799 y 1.044 .657 personas, respectivamente. De ahí la conveniencia de resumir los cambios en la estructura anteriormente descrita teniendo en cuenta estos crecimientos. Ese resumen conforma la siguiente tabla, que llama diferencia relativa a la resultante de dividir la población de 2006 por la de 1996 en cada categoría (multiplicada por 100 en la tabla 7).

7. De mayor a menor, los andaluces son: Sevilla, Málaga, Córdoba, Granada, Jerez de la Frontera, Almería, Huelva, Cádiz, Marbella, Jaén, Dos Hermanas y Algeciras. En el mismo orden, los catalanes son: Barcelona, Hospitalet de Llobregat, Badalona, Sabadell, Terrassa, Tarragona, Lérida, Santa Coloma de Gramenet, Mataró y Reus.

8. Tampoco lo tiene llamar población urbana a cualquiera de las contenidas en una urbanización con cientos de miles o millones de personas. Ello resulta evidente al señalar a las grandes ciudades de los países en vías de desarrollo, pero también valen como ejemplos algunas gigantescas urbanizaciones de países desarrollados. 
Tabla 6. Porcentajes de población por tamaño de municipio según comunidad autónoma y año

\begin{tabular}{lcccccc}
\hline & \multicolumn{2}{l}{$\mathbf{2 0 0 6}$} & & \multicolumn{1}{l}{$\mathbf{1 9 9 6}$} & \\
\cline { 2 - 3 } & Andalucía & Cataluña & & Andalucía & Cataluña \\
\hline 2.000 hab. & 3,35 & 5,05 & & 4,02 & 6,38 \\
$2.001-10.000$ hab. & 17,72 & 14,11 & & 19,78 & 14,01 \\
10.001-50.000 hab. & 28,46 & 25,37 & & 29,40 & 23,25 \\
50.001-100.000 hab. & 13,39 & 12,41 & & 10,25 & 9,65 \\
$>100.000$ hab. & 37,07 & 43,05 & & 36,55 & 46,70 \\
\hline Total & 100 & 100 & 100 & 100 \\
\hline
\end{tabular}

Fuente: INE. Elaboración propia.

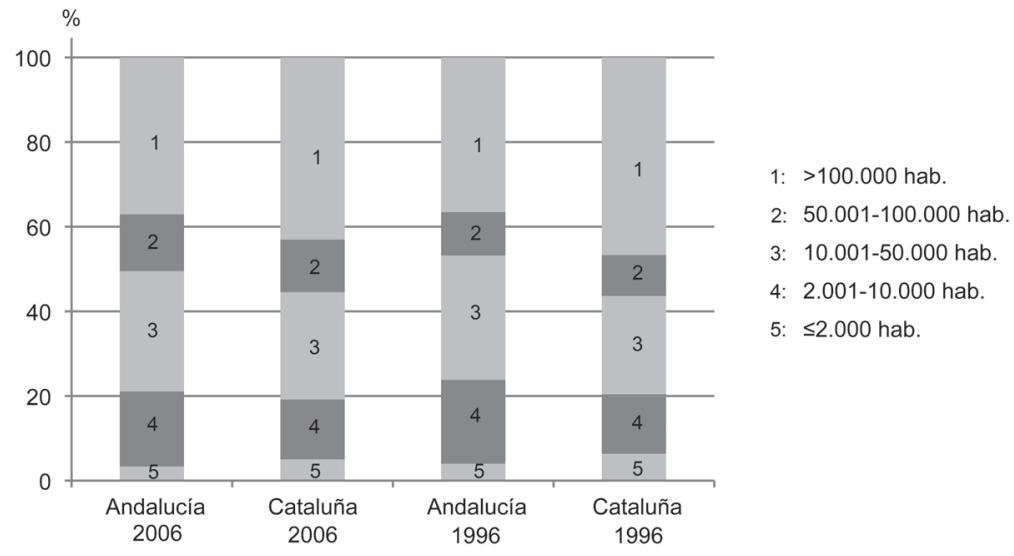

Gráfico 5. Estructura demográfica según población municipal, comunidad autónoma y año. Fuente: datos de la tabla 6.

Tabla 7. Cambio demográfico según tamaño de población municipal (1996-2006)

\begin{tabular}{|c|c|c|c|c|}
\hline & \multicolumn{2}{|l|}{ Andalucía } & \multicolumn{2}{|l|}{ Cataluña } \\
\hline & $\begin{array}{l}\text { Diferencia } \\
\text { absoluta }\end{array}$ & $\begin{array}{l}\text { Diferencia } \\
\text { relativa }\end{array}$ & $\begin{array}{l}\text { Diferencia } \\
\text { absoluta }\end{array}$ & $\begin{array}{l}\text { Diferencia } \\
\text { relativa }\end{array}$ \\
\hline Total & 740.799 & 110,24 & 1.044 .657 & 117,15 \\
\hline$\leq 2.000$ & -23.394 & 91,96 & -28.578 & 92,65 \\
\hline $2.001-10.000$ & -17.777 & 98,76 & 154.260 & 118,09 \\
\hline $10.001-50.000$ & 142.980 & 106,72 & 393.882 & 127,81 \\
\hline $50.001-100.000$ & 326.310 & 144 & 297.535 & 150,61 \\
\hline$>100.000$ & 312.680 & 111,82 & 227.558 & 108 \\
\hline
\end{tabular}

Fuente: INE. Elaboración propia. 
En números absolutos, sólo los municipios menores ( $\leq 2.000$ habitantes) han perdido población en ambas comunidades. Tal como su cuantía induce a pensar, esta pérdida se debe a causas naturales y no a un balance migratorio negativo. Estos municipios pierden población, pero no la trasvasan?

El tamaño 2.001-10.000 pierde muy poca población en Andalucía. No ocurre igual en Cataluña, donde gana en valor absoluto, puesto que su crecimiento relativo $(118,09)$ es algo superior al de la población total de la comunidad $(117,15)$.

El tamaño 10.001-50.000 es el de mayor diferencia entre ambas comunidades, pues si en Andalucía su crecimiento es inferior al de la población total $(106,72$ a 110,24), en Cataluña es superior en diez puntos $(127,81$ a 117,15).

El tamaño 50.001-100.000 es el de mayor crecimiento en ambas comunidades. Se trata, principalmente, de flujos residenciales hacia las primeras y segundas coronas metropolitanas. Un proceso de suburbanización de la población, que no de desurbanización, común a ambas comunidades, pero más acentuado en Cataluña.

El escaso crecimiento de los municipios mayores de 100.000 habitantes refuerza la evidencia del proceso de suburbanización. Aunque positivo, en Cataluña este crecimiento es inferior a su crecimiento total en 9,15 puntos, mientras que en Andalucía es 1,58 puntos superior. Pero es difícil sacar conclusiones comparables debido a la influencia de la extensión del término municipal en el reflejo estadístico de este proceso. La suburbanización no implica igual trasvase de población en Andalucía que en Cataluña. Basta un dato para considerar la distorsión del fenómeno que pueden provocar las cifras de población migrante: los diez municipios catalanes con más de 100.000 habitantes suman 597,32 kilómetros de superficie, los doce municipios andaluces de ese rango poblacional suman 4.315,29 (una extensión más que siete veces superior). En Andalucía puede producirse suburbanización sin pérdida de población en el mayor rango municipal, mientras que en Cataluña un proceso de suburbanización de igual o mayor magnitud queda reflejado en la estadística como trasvase de población entre municipios de diferente rango.

9. En la mayor población catalana de los municipios menores influye el mayor número de municipios catalanes. El total de municipios andaluces es 770, el de catalanes es 946. La provincia andaluza con más municipios es Granada, con 168, y la catalana con menos es Tarragona, con 183.

Número de municipios según rango demográfico en 2006

\begin{tabular}{lcc}
\hline & Andalucía & Cataluña \\
\hline$\leq 2.000$ & 307 & 612 \\
$2.001-10.000$ & 318 & 223 \\
$10.001-50.000$ & 117 & 88 \\
$50.001-100.000$ & 16 & 13 \\
$>100.000$ & 12 & 10 \\
\hline
\end{tabular}

Fuente: INE. 
En ambas comunidades, los jóvenes salen de los municipios menos poblados buscando mejores oportunidades laborales y/o educativas y los mayores entran en ellos por un movimiento (de retorno o no) relacionado con el término de la vida laboral. Estos flujos indican que ambas comunidades comparten una pauta general de movilidad residencial: desde el mayor tamaño a los menores. Presentan, sin embargo, diferencias que se explican en parte por una estructura demográfica andaluza más joven, con más salidas desde los menores tamaños, esto es, más movilidad residencial de acoplamiento de recursos y menos retornos o llegadas a los tamaños menores. De ahí las diferencias tan acusadas en los rangos segundo (2.001-10.000) y tercero (10.001-50.000), más atractivos para los catalanes que para los andaluces.

Las diferencias de edad de la población también resumen los procesos de «modernización territorial» de ambas comunidades. La edad media de los diferentes tamaños municipales es la que se aprecia en la tabla 8 .

En Andalucía, han envejecido todas las categorías de municipio salvo el tamaño de 50.000 a 100.000 habitantes. El envejecimiento ha sido de seis años en el tamaño $\leq 2.000$ e inferior a un año en las poblaciones de $10.001 \mathrm{a}$ 50.000 y mayores de 100.000 . En Cataluña, envejecen tres tamaños y rejuvenecen dos. Algunas diferencias entre años y comunidades son de pequeño grado y otras dibujan procesos diferenciados. Tres diferencias son más acusadas: (1) el mayor envejecimiento del mayor tamaño en Cataluña; (2) el contraste entre lo que ocurre en el tamaño 50.000-100.000, que en Andalucía ha rejuvenecido tres años y en Cataluña ha envejecido casi dos, y (3) el contraste de lo ocurrido en el tamaño 2.001-10.000, que en Andalucía envejece y en Cataluña rejuvenece.

En Andalucía, los dos tamaños mayores tienen una edad media de su población inferior a la de la comunidad. En Cataluña, los tres tamaños intermedios son más jóvenes que el conjunto. En conclusión, la renovación demográfica en Cataluña presenta mayor amplitud territorial que en Andalucía. Desde otra perspectiva, puede decirse que en Andalucía la despoblación de determinados municipios es mayor que en Cataluña, cuya vitalidad demográfica durante los últimos años se observa donde no se observa en Andalucía.

Tabla 8. Media de edades según tamaño del municipio, comunidad autónoma y año

\begin{tabular}{llllll}
\hline & Andalucía & & & Cataluña & \\
\cline { 2 - 3 } \cline { 5 - 6 } & $\mathbf{1 9 9 5}$ & $\mathbf{2 0 0 6}$ & & $\mathbf{1 9 9 5}$ & $\mathbf{2 0 0 6}$ \\
\hline Total & 43,7 & 44,3 & & 45 & 46,5 \\
\hline$\leq 2.000$ & 45,7 & 51,7 & & 45,2 & 51,9 \\
$2.001-10.000$ & 44 & 45,5 & 45,4 & 45 \\
$10.001-50.000$ & 44,2 & 44,9 & 45 & 44,8 \\
$50.000-100.000$ & 43 & 40 & 44 & 45,9 \\
$>100.000$ & 43,2 & 43,6 & 45 & 47,4 \\
\hline
\end{tabular}

Fuente: ASEP. 


\section{Migración interior y modernización}

Las tablas siguientes (tablas 9 y 10) pretenden resumir la movilidad geográfica en el interior de España de andaluces y catalanes en los años 2000 y 2005. Las columnas que suceden a la del territorio indican el porcentaje de población de ese territorio que ha cambiado de residencia en ese año. La primera de estas columnas indica el porcentaje de población que cambió su municipio de residencia dentro de la misma provincia; la segunda, el de quienes cambiaron a otra provincia de la misma comunidad; la tercera, el de quienes cambiaron a otra comunidad española, y la última (suma de las anteriores), el porcentaje total de quienes cambiaron su municipio de residencia dentro de España. Los porcentajes pueden ser engañosos si se sobredimensiona el sentido de nuestra movilidad geográfica, pues quienes han cambiado de municipio dentro de la misma provincia, la mayoría en todos los casos, realizan por lo general un cambio de residencia que no conlleva cambio de actividad o modo de vida, que no implica migración, como ocurre con la mayor parte de la actual movilidad no recurrente de españoles, andaluces y catalanes ${ }^{10}$.

Tabla 9. Porcentaje de población que ha cambiado de residencia (año 2000)

\begin{tabular}{lllll}
\hline & $\begin{array}{l}\text { En la misma } \\
\text { provincia }\end{array}$ & $\begin{array}{l}\text { A otra provincia } \\
\text { de la comunidad }\end{array}$ & A otra comunidad & Total \\
\hline Andalucía & 1,17 & 0,37 & 0,65 & 2,19 \\
\hline Almería & 1,48 & 0,38 & 0,98 & 2,84 \\
Cádiz & 0,93 & 0,36 & 0,78 & 2,07 \\
Córdoba & 0,54 & 0,41 & 0,68 & 1,63 \\
Granada & 1,75 & 0,49 & 0,76 & 3,00 \\
Huelva & 1,12 & 0,44 & 0,43 & 1,99 \\
Jaén & 0,66 & 0,40 & 0,76 & 1,82 \\
Málaga & 1,35 & 0,29 & 0,44 & 2,08 \\
Sevilla & 1,32 & 0,32 & 0,56 & 2,20 \\
\hline Cataluña & 2,31 & 0,43 & 0,47 & 3,21 \\
Barcelona & 2,47 & 0,36 & 0,46 & 3,29 \\
Gerona & 2,19 & 0,69 & 0,45 & 3,33 \\
Lérida & 1,06 & 0,72 & 0,53 & 2,31 \\
Tarragona & 1,95 & 0,62 & 0,54 & 3,11 \\
\hline
\end{tabular}

Fuente: INE. Elaboración propia.

10. Las cifras de emigraciones anuales al exterior se han obviado. Para ser leídas con facilidad, han de serlo en unidades por cada diez mil habitantes (su contribución a la movilidad general es poco apreciable). En 2005, emigraron al extranjero 2.108 españoles desde Andalucía y 3.358 desde Cataluña. Los andaluces y catalanes residentes en el extranjero eran 140.227 y 109.001, respectivamente (a 1 de enero de 2007). 
Tabla 10. Porcentaje de población que ha cambiado de residencia (año 2005)

\begin{tabular}{lllll}
\hline & $\begin{array}{l}\text { En la misma } \\
\text { provincia }\end{array}$ & $\begin{array}{l}\text { A otra provincia } \\
\text { de la comunidad }\end{array}$ & A otra comunidad & Total \\
\hline Andalucía & 1,32 & 0,41 & 0,43 & 2,16 \\
\hline Almería & 1,44 & 0,32 & 0,43 & 2,20 \\
Cádiz & 0,96 & 0,42 & 0,56 & 1,43 \\
Córdoba & 0,62 & 0,46 & 0,49 & 1,57 \\
Granada & 2,23 & 0,47 & 0,56 & 3,26 \\
Huelva & 1,40 & 0,46 & 0,33 & 2,19 \\
Jaén & 0,72 & 0,43 & 0,65 & 1,80 \\
Málaga & 1,36 & 0,48 & 0,23 & 2,07 \\
Sevilla & 1,55 & 0,32 & 0,38 & 2,25 \\
\hline Cataluña & 2,32 & 0,51 & 0,54 & 3,37 \\
Barcelona & 2,50 & 0,41 & 0,56 & 3,47 \\
Gerona & 1,98 & 0,82 & 0,44 & 3,24 \\
Lérida & 1,40 & 0,80 & 0,45 & 2,65 \\
Tarragona & 1,81 & 0,71 & 0,54 & 3,06 \\
\hline
\end{tabular}

Fuente: INE. Elaboración propia.

La diferencia de 1,21 puntos porcentuales en la movilidad total de ambas comunidades para el 2005 es apreciable en números absolutos, pues se traduce en 89.268 desplazados más en Cataluña que en Andalucía. La distancia del año 2000, de 1,02 puntos porcentuales, implicó el desplazamiento de 40.263 personas más en Cataluña. Estos son los valores que hacen percibir más la diferencia en la movilidad general entre una y otra comunidad ${ }^{11}$.

Los datos permiten también realizar otras consideraciones que relativizan esa diferencia. Quizás el aspecto principal sea que la provincia de Barcelona contribuye de forma especial a establecer la mayor movilidad catalana. Barcelona suma el $74,4 \%$ de la población catalana, por contraste con lo que ocurre en Andalucía, donde las cuatro provincias más pobladas (Sevilla, Málaga, Cádiz y Granada) suman el 67,7\% de la población andaluza. Es precisamente Barcelona la provincia con mayor movilidad interior de las doce que comprenden los territorios estudiados, con movimientos que se producen dentro de la Región Metropolitana de Barcelona.

11. La encuesta ECHP (European Community Household Panel) permite comparar la movilidad interior de los países europeos. Las movilidades mayores se observan actualmente en Dinamarca, Finlandia y Reino Unido, y la más baja, en Italia, a poca distancia de la cual se encuentra España, con valores parecidos a los de Austria, Irlanda, Grecia y Portugal (junto con Luxemburgo, con la que, por su dimensión territorial y demográfica, entiendo que no cabe igual comparación). 
Por su parte, Lérida y Tarragona, las provincias catalanas históricamente más expulsoras de población (tabla 1), dan muestras de haber completado su «transición demográfica» de acoplamiento entre recursos productivos, pues en la presente década sus migraciones no se diferencian por su dirección de las del conjunto de Cataluña (tablas 9 y 10). La mayoría no sale de la provincia y son minoría las que se dirigen fuera de la comunidad. El dato es congruente con la hipótesis validada por Gobernado y Herrera hace diez años, ya que el PIB per cápita y la tasa de paro presentan variaciones mínimas entre las provincias catalanas (los peores datos son los de Barcelona).

En el caso contrario (y por efecto de la misma ecuación) estarían las andaluzas Córdoba y Jaén, ya que en ambas el destino principal de sus migraciones es otra comunidad autónoma, tanto en un pasado más lejano (tabla 1), como en otro más reciente (tabla 9). En efecto, los PIB per cápita de Jaén y Córdoba son los más bajos entre los andaluces y sus tasas de paro son superiores a las de la media andaluza. En síntesis, estos datos sugieren que en Cataluña el desarrollo interprovincial es más homogéneo que en Andalucía.

La tabla siguiente (tabla 11) resume la homogeneidad o heterogeneidad interprovincial (territorial) dentro de cada comunidad, medida a través del PIB per cápita y la tasa de paro ${ }^{12}$.

El mismo procedimiento se aplica a continuación a los datos proporcionados por ASEP. Los valores en columnas expresan diferencias porcentuales con la media de la comunidad en ese año (un valor negativo es inferior y uno positivo es superior a la media en la medida porcentual del valor), según las cinco categorías demográficas utilizadas antes: $\leq 2.000$, 2.001-10.000, 10.00150.000, 50.001-100.000 y >100.000. (Cada uno de estos valores se divide por cien y se calcula el cuadrado de la división.) La suma de cada fila proporciona un índice de heterogeneidad. La heterogeneidad se mide con tres variables proporcionadas por la base de datos ASEP: nivel educativo del entrevistado (1995 y 2006), ingresos de la unidad familiar (1995 y 2006) y tasa de paro (2006) (tablas 12, 13 y 14).

12. Los PIB per cápita de Cataluña y Andalucía eran, en 2004 (publicados en 2006), de 23.532 y 15.154 euros y sus tasas de paro del 6,6\% y $12,7 \%$, en 2006 , respectivamente. En las columnas «variación», aparece el resultado de dividir el valor provincial por el comunitario (y multiplicarlo por 100). Los valores provinciales de las columnas «índice» apenas tienen utilidad por sí mismos, pero se emplean para la obtención del índice comunitario de desigualdad (el propósito de la tabla), que resulta de la suma de los cuadrados de las diferencias provinciales (divididas por 100, antes de la potenciación). Este índice facilita la comparación, pero no una idea de la medida de lo indicado; y, como es obvio pero merece subrayarse, se refiere a la heterogeneidad provincial, no a la desigualdad social interpersonal. 
Tabla 11. Heterogeneidad interior de Andalucía y Cataluña en 2006

\begin{tabular}{lcccc}
\hline & PIB per cápita & $\begin{array}{l}\text { Índice de } \\
\text { heterogeneidad }\end{array}$ & Tasa de paro & $\begin{array}{c}\text { Índice de } \\
\text { heterogeneidad }\end{array}$ \\
\hline Andalucía & $(100)$ & 0,177 & $(100)$ & 0,186 \\
\hline Almería & 121,62 & 21,62 & 74,80 & $-25,20$ \\
Cádiz & 100,61 & 0,61 & 121,26 & 21,26 \\
Córdoba & 88,09 & $-11,91$ & 113,38 & 13,38 \\
Granada & 90,51 & $-9,49$ & 85,83 & $-14,17$ \\
Huelva & 105,57 & 5,57 & 113,38 & 13,38 \\
Jaén & 87,10 & $-12,90$ & 108,66 & 8,66 \\
Málaga & 103,64 & 3,64 & 88,19 & $-11,81$ \\
Sevilla & 102,66 & 2,66 & 101,57 & 1,57 \\
Cataluña & $(100)$ & 0,003 & $(100)$ & 0,004 \\
Barcelona & 98,98 & $-1,02$ & 101,51 & 1,51 \\
Gerona & 102,23 & 2,23 & 100 & 0 \\
Lérida & 102,97 & 2,97 & 95,45 & $-4,55$ \\
Tarragona & 103,87 & 3,87 & 95,45 & $-4,55$ \\
\hline
\end{tabular}

Fuente: INE. Elaboración propia.

Tabla 12. Heterogeneidad interior de Andalucía y Cataluña según nivel educativo, tamaño del municipio y año

\begin{tabular}{|c|c|c|c|c|c|c|}
\hline & $\leq 2.000$ & $\begin{array}{l}2.001- \\
10.000\end{array}$ & $\begin{array}{l}10.001- \\
50.000\end{array}$ & $\begin{array}{l}50.001- \\
100.000\end{array}$ & $>100.000$ & $\begin{array}{l}\text { Índice de } \\
\text { heterogeneidad }\end{array}$ \\
\hline $\begin{array}{l}\text { Andalucía } \\
(1995)\end{array}$ & $-12,63$ & $-18,69$ & $-16,84$ & 0,34 & 22,73 & 0,1308 \\
\hline $\begin{array}{c}\text { Andalucía } \\
(2006)\end{array}$ & $-13,64$ & $-10,46$ & $-5,43$ & 8,21 & 8,21 & 0,0539 \\
\hline $\begin{array}{l}\text { Cataluña } \\
\text { (1995) }\end{array}$ & $-10,60$ & $-7,46$ & $-9,16$ & $-2,23$ & 19,63 & 0,0642 \\
\hline $\begin{array}{c}\text { Cataluña } \\
\text { (2006) }\end{array}$ & -5 & $-6,39$ & $-0,54$ & $-2,6$ & 3,03 & 0,0082 \\
\hline
\end{tabular}

Fuente: ASEP. Elaboración propia. 
Tabla 13. Heterogeneidad interior de Andalucía y Cataluña según ingresos del hogar, tamaño del municipio y año

\begin{tabular}{lllllll}
\hline & $\leq 2.000$ & $\mathbf{1 0 . 0 0 0}$ & $\mathbf{5 0 . 0 0 0}$ & $\mathbf{1 0 0 . 0 0 0}$ & $>100.000$ & $\begin{array}{l}\text { Índice de } \\
\text { heterogeneidad }\end{array}$ \\
\hline $\begin{array}{c}\text { Andalucía } \\
(1995)\end{array}$ & $-7,85$ & $-10,07$ & $-9,76$ & $-11,48$ & 17,28 & 0,0688 \\
$\begin{array}{c}\text { Andalucía } \\
(2006)\end{array}$ & $-13,02$ & $-10,18$ & $-0,73$ & 22,60 & 1,90 & 0,0788 \\
$\begin{array}{c}\text { Cataluña } \\
(1995)\end{array}$ & $-5,80$ & $-1,13$ & $-4,97$ & $-18,42$ & 15,34 & 0,0634 \\
$\begin{array}{c}\text { Cataluña } \\
(2006)\end{array}$ & 10,56 & 1,65 & 1,22 & $-8,11$ & $-3,49$ & 0,0193 \\
\hline
\end{tabular}

Fuente: ASEP. Elaboración propia.

Tabla 14. Heterogeneidad interior de Andalucía y Cataluña según la tasa de paro y tamaño del municipio (año 2006)

\begin{tabular}{crrrrrl}
\hline & & $2.001-$ & $\mathbf{1 0 . 0 0 1 -}$ & $50.001-$ & & Índice de \\
& $\leq 2.000$ & $\mathbf{1 0 . 0 0 0}$ & $\mathbf{5 0 . 0 0 0}$ & $\mathbf{1 0 0 . 0 0 0}$ & $>100.000$ & heterogeneidad \\
\hline $\begin{array}{c}\text { Andalucía } \\
(2006)\end{array}$ & $-63,7$ & 2,75 & 23,22 & 26 & $-53,40$ & 0,8131 \\
$\begin{array}{c}\text { Cataluña } \\
(2006)\end{array}$ & $-76,97$ & $-21,74$ & $-10,81$ & 43,48 & $-40,89$ & 1,0075 \\
\hline
\end{tabular}

Fuente: ASEP. Elaboración propia.

El mismo procedimiento permite obtener índices comunitarios (sumando por filas) y municipales (sumando por columnas) (tabla 15).

La tabla 16 presenta los saldos comunitarios de población, ingresos del hogar y nivel educativo del período 1996-2006 (se llama saldo de ingresos y saldo educativo a las variaciones porcentuales entre esos años: valor del 2006 dividido por valor del 1995 y multiplicado por 100).

Puestos en relación los crecimientos en el período de las tres variables (tabla 16) mediante regresión (tabla 17), son las variaciones demográficas y en el nivel de ingresos las que presentan un resultado más significativo (tomando la variación de los ingresos como variable dependiente y la variación de población como independiente). 
Tabla 15. Heterogeneidad interior de Andalucía y Cataluña según tamaño de municipio y varios indicadores

\begin{tabular}{|c|c|c|c|c|c|}
\hline & $\leq 2.000$ & $\begin{array}{l}2.001- \\
10.000\end{array}$ & $\begin{array}{l}10.001- \\
50.000\end{array}$ & $\begin{array}{l}50.001- \\
100.000\end{array}$ & $>100.000$ \\
\hline \multicolumn{6}{|l|}{ Andalucía 1995} \\
\hline Nivel educativo & $-12,63$ & $-18,69$ & $-16,84$ & 0,34 & 22,73 \\
\hline Ingresos hogar & $-7,85$ & $-10,07$ & $-9,76$ & $-11,48$ & 17,28 \\
\hline Índice de heterogeneidad & 0,0221 & 0,045 & 0,0378 & 0,0132 & 0,0815 \\
\hline \multicolumn{6}{|l|}{ Andalucía 2006} \\
\hline Nivel educativo & $-13,64$ & $-10,46$ & $-16,84$ & 8,21 & 8,21 \\
\hline Ingresos hogar & $-13,02$ & $-10,18$ & $-0,73$ & 22,6 & 1,9 \\
\hline Índice de heterogeneidad & 0,0355 & 0,0213 & 0,0283 & 0,0578 & 0,0071 \\
\hline \multicolumn{6}{|l|}{ Cataluña 1995} \\
\hline Nivel educativo & $-10,6$ & $-7,46$ & $-9,16$ & $-2,23$ & 19,63 \\
\hline Ingresos hogar & $-5,8$ & $-1,13$ & $-4,97$ & $-18,42$ & 15,34 \\
\hline Índice de heterogeneidad & 0,0146 & 0,0057 & 0,0109 & 0,0344 & 0,062 \\
\hline \multicolumn{6}{|l|}{ Cataluña 2006} \\
\hline Nivel educativo & -5 & $-6,39$ & $-0,54$ & $-2,6$ & 3,03 \\
\hline Ingresos hogar & 10,56 & 1,65 & 1,22 & $-8,11$ & $-3,49$ \\
\hline Índice de heterogeneidad & 0,0111 & 0,0044 & 0,0001 & 0,0073 & 0,0021 \\
\hline
\end{tabular}

Fuente: ASEP. Elaboración propia.

Tabla 16. Crecimiento del período 1996-2006 según comunidad autónoma, tamaño del municipio y varios indicadores

\begin{tabular}{llllllll}
\hline & \multicolumn{2}{l}{ Andalucía } & & & \multicolumn{2}{l}{ Cataluña } \\
\cline { 2 - 3 } \cline { 7 - 8 } & Ingresos & Educativo & Demográfico & & Ingresos & Educativo & Demográfico \\
\hline Total & 172,77 & 127,10 & 110,24 & & 133,30 & 120,81 & 117,15 \\
$\leq 2.000$ & 163,37 & 125,62 & 91,96 & & 156,45 & 128,40 & 92,65 \\
$2.001-10.000$ & 172,57 & 139,96 & 98,76 & & 137,05 & 122,20 & 118,09 \\
$10.001-50.000$ & 190,06 & 144,53 & 106,72 & & 142 & 132,27 & 127,81 \\
$50.000-100.000$ & 239,29 & 137,08 & 144 & & 150,15 & 120,35 & 150,61 \\
$>100.000$ & 150,11 & 110,85 & 111,82 & & 156,62 & 115,41 & 108 \\
\hline
\end{tabular}

Fuentes: ASEP (crecimiento de ingresos y educación) e INE (demográfico). Elaboración propia.

Tabla 17. Análisis de regresión; $y=\varnothing$ ingresos, $x=\varnothing$ población, $y=\varnothing$ nivel educativo, $x=\varnothing$ población

\begin{tabular}{lllllll}
\hline & b0 & b1 & R cuadrado & b0 & b1 & R cuadrado \\
\hline Andalucía & 0,55 & 1,16 & 0,48 & 1,26 & 0,005 & 0,006 \\
Cataluña & 1 & 0,39 & 0,13 & 0,99 & 0,22 & 0,01 \\
\hline
\end{tabular}




\section{Epílogo y comentario de las tablas anteriores}

Pese a no ser centro del interés sociológico, las condiciones geográficas no deben ser ignoradas en un estudio sobre movilidad geográfica. La superficie de Andalucía es de 87.598 kilómetros, la de Cataluña, de 32.113. Como se ha mencionado, en 2006 Andalucía contaba con 770 municipios y Cataluña, con 946. Esta diferencia numérica es mayor en los municipios de menor rango. En Cataluña hay más poblaciones pequeñas, habitadas por personas de semejante edad media que en Andalucía, que no por ello viven al margen de la modernización ${ }^{13}$.

La pérdida absoluta de población en los municipios menores durante el período 1996-2006, tanto en Andalucía como en Cataluña, se ha debido a la pérdida natural de su población ("crecimiento vegetativo negativo»), pero su saldo migratorio ha sido positivo. La homogeneidad socioeconómica que define la modernización y la supervivencia del menor rango municipal son lados del mismo poliedro, ya que «la mancha de aceite» sólo puede extenderse sobre una superficie de densidad suficiente, una red de grupos locales que proporcione opciones residenciales a una población con mayor margen de elección individual ${ }^{14}$. La modernización reduce el número y la población de los municipios menores hasta determinado umbral (representado gráficamente por la curva superior de la $S$ ). Un paisaje compuesto de grandes aglomeraciones humanas y extensas áreas despobladas, más característico de Andalucía que de Cataluña, es contrario a la homogeneidad. El grupo local catalán de menor tamaño está menos aislado que el andaluz de igual o incluso mayor tamaño. La mayor densidad facilita el acceso a los bienes y servicios (desde conexión ADSL hasta prestación sanitaria). En consecuencia, la modernización llega allá donde lo hacen las prácticas que la definen, y esa extensión es más fluida también por causas geográficas en Cataluña que en Andalucía. El entramado municipal es una herencia histórica que favorece el desarrollo modernizador. Las que siguen a continuación son algunas conclusiones del proceso modernizador durante los doce años observados.

13. El mejor ejemplo es la Región Metropolitana de Barcelona (RMB), que cuenta con 164 municipios.

14. Lo que está cambiando es la idea misma de localización. Los criterios para la localización varían con las circunstancias de los habitantes. Unos se guiarán por la distancia al aeropuerto internacional más próximo y otros por el consumo de tiempo en los trayectos de ida y vuelta al trabajo. Para los padres con hijos menores de edad, la distancia al colegio elegido para sus hijos será una coordenada principal, y para los mayores de determinada edad, la distancia al centro sanitario más próximo. Esta «modernización residencial» consistirá en que la localización de un grupo local será definida de formas diferentes por sus miembros. Con independencia de la evidencia geométrica o geográfica, los individuos de un mismo grupo local modernizado no comparten la misma ubicación subjetiva. Esta disparidad contribuye a realizar la evolución de la identidad local (no a hacerla desaparecer) y proporciona una ocasión para subrayar que la modernización no desclasifica (descategoriza o individúa) a los individuos, sino que los reclasifica (recategoriza). 
Primera: los desplazamientos mayoritarios en ambas comunidades, que se reflejan en la pérdida relativa y absoluta de población de los municipios mayores, no configuran un proceso de retrorruralización, sino de hiperurbanización. Paralelamente, se produce una devaluación de los indicadores de bienestar y modernización del mayor tamaño, notoria en el municipio de Barcelona y menos acusada en los mayores municipios andaluces, pues quienes migran o cambian no lo hacen tanto movidos por la necesidad funcional como por un ideal de bienestar.

Segunda: las dificultades para la categorización de los migrantes interiores en Andalucía y, más aún, en Cataluña derivan de los aspectos siguientes: (1) de la generalización del ideal residencial, (2) de la escasa interrelación entre el domicilio de residencia y el de trabajo y (3) de que la mayoría de la movilidad no recurrente es efecto de un cambio de residencia y no de un cambio laboral.

Tercera: como apuntan otras investigaciones recientes, los parados son quienes menos cambian de residencia, puesto que la carencia de trabajo no les moviliza a través del territorio, al contrario. Es la actividad la que moviliza, y ello promueve que aumente la movilidad recurrente y se extienda la urbanización a las zonas de transición. Entre las variables consideradas para medir la heterogeneidad territorial (PIB per cápita, ingresos familiares, nivel educativo y tasa de paro), la última se reparte algo más igualitariamente en Andalucía que en Cataluña. Son mayoría los parados que no salen de su localidad o provincia de residencia para buscar trabajo, en todo caso, salen si lo encuentran; y es comprensible que sea más de este modo cuanto más igualitariamente se reparta el desempleo o el trabajo a lo largo del territorio. Ocurre en Andalucía, con una tasa de paro del $12,7 \%$, y en Cataluña, con una tasa de paro del $6,5 \%$. En ambas comunidades, la tasa de paro es menor en los municipios menores $(\leq 2.000)$, donde la mayoría de la población es inactiva, y mayores (>100.000), donde la mayoría es ocupada, los dos rangos que han perdido población (en términos relativos o absolutos). La razón de esta escasa movilización es la utilidad decreciente de asumir un coste, el de la migración o el cambio, a partir de un determinado nivel de bienestar compartido ${ }^{15}$. Entre Andalucía y Cataluña las diferencias son notables, en la productividad, en el nivel de estudios, en las tasas de actividad y desempleo, etc., pero las circunstancias socioeconómicas hacen en ambas comunidades que el comportamiento de su población apenas

15. No debería sorprender la compatibilidad de una tasa de paro alta y una migración baja. Cambiar de residencia por un trabajo (o cualquier otra recompensa) sólo interesa si la recompensa es mayor que el coste. Las recompensas salariales y los costes de una mudanza serán evaluados racionalmente por el potencial trabajador, salvo cuando la necesidad, la desesperación o el hastío le priven de la posibilidad de elegir (en cuyo caso también puede haber decisión racional, como la de hacer el bien aunque no haya amenaza de sanción ni recompensa posible). Son ésas las circunstancias que sufren millones de personas en el mundo, pero no las sufren la mayoría de los andaluces. 
esté influenciado por la necesidad (y sea menos previsible el inducido por ella), pues ambas han rebasado ese umbral de modernización (o desarrollo) que libera el comportamiento del esfuerzo para satisfacer determinadas necesidades.

Cuarta: ¿se han acercado en el último decenio Andalucía y Cataluña en el grado de modernización? ¿Cómo ha influido en esta convergencia o esta divergencia el movimiento de la población? Los datos manejados en este capítulo describen una divergencia estrechamente relacionada con el movimiento de población.

Tanto la desigualdad interprovincial como la intermunicipal son menores en Cataluña que en Andalucía, pero, además, la segunda aumentó en Andalucía y se redujo en Cataluña durante los últimos años.

La ganancia en el nivel educativo se vio acompañada en ambas comunidades de un reparto intermunicipal más equitativo de este bien, más en Cataluña que en Andalucía (debido especialmente a la mayor migración catalana desde el mayor tamaño).

En los ingresos familiares declarados, el reparto intermunicipal es ahora más igualitario en Cataluña y menos en Andalucía.

En Andalucía, están por debajo de la ganancia general los ingresos y el nivel educativo del mayor y menor tamaño municipales. En el menor tamaño, esa circunstancia contribuye a la desigualdad intermunicipal (sin beneficiarios) y en el mayor, a la igualdad (con beneficiarios). En Cataluña, los cinco rangos municipales contemplados se han acercado a los valores medios de la comunidad. En cuatro de los rangos, la igualación es efecto de la mejora y sólo en el mayor lo es de la merma relativa de sus niveles de ingresos y formación.

La mejora en el nivel educativo se observa generalizada, salvo en los municipios andaluces menores $(\leq 2.000)$, envejecidos y despoblados, y en los andaluces y catalanes mayores $(>100.000)$, repoblados mediante procesos de sustitución demográfica que son evidentes en la Región Metropolitana de Barcelona y no así en las mayores ciudades andaluzas, y menos relacionada con el movimiento de población, como corresponde a una mejora social. En cambio, se observa una relación, significativa en el caso catalán e importante en el andaluz, entre el crecimiento demográfico y el de los ingresos familiares.

En Andalucía (durante los años observados), el aumento de renta se ha debido al de población y la merma de renta ha sido efecto de la pérdida de población en bastante medida. No ha ocurrido de igual forma o en la misma medida en Cataluña. Ésta es una fórmula insostenible, puesto que no se puede mejorar a costa de crecer indefinidamente. Por ello, cabe concluir que la homogeneidad territorial es indicador y efecto de la modernización, pero también una condición y un factor para su continuidad. 


\section{Referencias bibliográficas}

Alberich GonZÁleZ, J. (2003). «Cambio de vivienda y contextos sociales y residenciales en Europa». Papers de Demografía, 228.

Antolín, P. y Bover, O. (1997). «Regional migration in Spain: The effect of personal characteristics and of unemployment, wage and house price differentials using pooled cross-sections». Oxford Bulletin of Economics and Statistics, 59, 215-235.

Ascher, F. (1995). Métapolis ou l'avenir des villes. París: Odile Jacob.

BARro, R. y SAla I MARTín, X. (1992). "Convergence across states and regions». Brookings Papers, 1.

BerICAT AlASTUEY, E. (1994). Sociología de la movilidad espacial: El sedentarismo nómada. Madrid: CIS. Monografías; 140.

Bentolila, S. (1997). «La inmovilidad del trabajo en las regiones españolas». Papeles de Economía Española, 72.

BÖHEIM, R. y TAYLOR, M. (1999). «Residential mobility, housing tenure and the labour market in Britain». ILR Working Paper, 35, University of Essex.

Bonvalet, C. y Fribourg, A.M. (1990). Stratégies résidentielles. París: Ined-Plan Construction et Architecture, MELTM.

Clark, W. y ONAKA, J. (1982). "Life cycle and housing adjustment as explanations of residential mobility». Urban Studies, 20, 47-57.

Faini, R.; Galli, G.; Gennari, P. y Rossi, F. (1997). «An empirical puzzle: Falling migration and growing unemployement differentials among Italian regions». European Economic Review, 41.

Feria Toribio, J.M. y Susino Arbucias, J. (coords.) (2005). Movilidad por razón de trabajo en Andalucía. 2001. Sevilla: Instituto de Estadística de Andalucía.

GARCía COLL, A. (2005). "Migraciones interiores y transformaciones territoriales». Papeles de Economía Española, 104, 76-91.

GOBERNADO ARRIBAS, R. (coord.) (1996). Análisis comparado de las estructuras sociales de Andalucía y Cataluña. Málaga: Servicio de Publicaciones Universitarias.

GrafMEYER, Y. y DANSEREAU, F. (1998). Trajectoires familiales et spaces de vie en milieu urbain. Lyon: Press Universitaires de Lyon.

Groenewold, N. (1997). "Does migration equalise regional unemployment rates? Evidence from Australia». Papers in Regional Science, 76.

Henley, A. (1998). "Residencial mobility, housing equity and the labour market». The Economic Journal, 108, 414-427.

Hierro, M. (2006). «Movilidad y dispersión espacial en las regiones españolas, 19862003». Investigaciones Regionales, 8, 163-170.

Hoover, E.M. (1948). The location of economic activity. Nueva York: McGraw Hill. Hughes, G. y MCCORMick, B. (1994). "Did migration in the 1980s narrow the North-South divide?». Economica, 61.

INGLEHART, R. y WELZEL, C. (2006). Modernización, cambio cultural y democracia: la secuencia del desarrollo humano. Madrid: CIS.

LELIÈVRE, E. y LÉVy-VROELANT, C. (eds.) (1992). La ville en mouvement: habitat et habitants. París: L’Harmattan.

LÓPEZ GAY, A. (2003). «Intensidad y calendario de la movilidad residencial en la Unión Europea». XVIII Congreso de la Asociación de Geógrafos Españoles. Barcelona.

Krugman, P. (1997). Desarrollo, geografía y teoría económica. Barcelona: Antoni Bosch, 78.

MCCORMicK, B. (1997). "Regional unemployment and labour mobility in the UK». European Economic Review, 61. 
Martínez Torres, M. (2005). «Migraciones interregionales en España y rentas mínimas, 1996-2004». XIII Congreso de Economía Pública. Almería.

Módenes, J.A. (2000). «Movilidad residencial y dinámica familiar de los adultos jóvenes urbanos en los 80». Papers de Demografía. Bellaterra: Centre d'Estudis Demogràfics, 170.

MolHo, I. (1995). «Migrant inertia, accessibility and local unemployment». Economica, 62.

MYRDAL, G. (1959). Teoría económica y regiones subdesarrolladas. México: FCE.

PujAdAs, I. y García Coll, A. (1995). «Migraciones interiores en España: tendencias recientes y perspectivas de futuro». Revista de Geografía, XXIX, 1-150.

PujADAS, I. (2005). De la ciudad compacta a la ciudad dispersa: movilidad residencial en la Región Metropolitana de Barcelona, 1982-2000. XXV Conferencia Internacional de la Población.

Puyol, R. (ed.) (1997). Dinámica de la población en España. Madrid: Síntesis.

RECAÑO, J. y CABRÉ, A. (2004). "Migraciones interregionales y ciclos económicos en España (1988-2001)». Papeles de Geografía, 37. Murcia.

Richardson, H.W. (1976). Politica y planificación del desarrollo regional en España. Madrid: Alianza Universidad.

ROMERO, J. y AlberTos, J.M. (1993). «Retorno al sur, desconcentración metropolitana y nuevos flujos migratorios en España». Revista Española de Investigaciones Sociológicas, 63, 123-144.

Rosés, J. y SÁnCHEZ-AlOnSO, B. (2004). «Regional wage convergence in Spain, 18531930». Explorations in Economic History, 41, 404-425.

Solana, A.M.; Miguel, V. de y Cardelús, J. (2004). «Características y evolución de las redes migratorias provinciales en España durante el siglo XX». VII Congreso de la Asociación de Demografía Histórica. Granada.

Susino, J.; DuQue, R. y Hernández Hurtado, D. (2006). «Las migraciones internas en Andalucía, principales flujos y protagonistas». III Congreso Andaluz de Sociología. Granada.

WALlersteIn, I. (1979). El moderno sistema mundial. México: Siglo XXI. 